\title{
Eliciting Accessibility Requirements for People with Hearing Loss: A Semantic and Norm Analysis
}

\author{
Marta Angélica Montiel Ferreira ${ }^{1}$ and Rodrigo Bonacin ${ }^{1,2}$ \\ ${ }^{1}$ FACCAMP, Rua Guatemala, 167, 13231-230, Campo Limpo Paulista, SP, Brazil \\ 2 CTI Renato Archer, Rodovia Dom Pedro I, km 143,6, 13069-901, Campinas, SP, Brazil \\ zmontefer@gmail.com, rodrigo.bonacin@cti.gov.br
}

\begin{abstract}
The barriers for people with hearing loss to access the Web go beyond the perceptual ones, i.e., the use of audio based content. Many people with hearing loss have difficulty writing and interpreting long or complex texts on the Web. In this study, we analyzed the semantic and normative aspects of Web content production and consumption by means of participatory studies with 29 deaf users. These studies resulted in the elicitation of 121 key problems, and the respective high level design recommendations. The recommendations aim to transform the Web into an inductor of learning. They also include design solutions that demand further research on assistive technologies
\end{abstract}

Keywords: Web Accessibility, Universal Design, Organizational Semiotics, Universal Usability.

\section{Introduction}

People with singular impairments have various usage barriers when navigating the web, including perceptual, cognitive, and social ones. A person with total hearing impairment can be understood as someone who is not able to understand the spoken language, regardless of amplification devices. There are multidisciplinary studies that explore alternatives for how to teach the written language to people that already know sign language. Despite advances in teaching practices, the level of comprehension of the written language amongst people with hearing loss varies from person to person.

Nowadays, although there is a large amount of visual information on the web, the predominant means of communication is still the written language. One of the challenges in the design of an accessible Web is how to understand the users' needs, what are their barriers during Web usage today, and their suggestions to remove or minimize these barriers.

Our previous studies [1], highlighted many difficulties for people with hearing loss using the Web. In these previous studies, we adapted two methods from the Problem Articulation Methods (PAM) [2]: the Semiotic framework (or Semiotic diagnosis) and the Evaluation framing (from the valuation framing) to analyze opinions and scenarios faced by internet users with hearing loss. 
The focus of this paper is to investigate the semantic and normative aspects of barriers for people with hearing loss producing and consuming Web content. This investigation aims to elicit a set of requirements and recommendations for the design of Web content and application, and of assistive technology. The methodology used during the analysis is based on Gibson's [3] affordances concept expanded by Stamper in the Semantic Analysis Method (SAM) and the Norm Analysis Method (NAM) $[2,4]$. The objective is to identify the affordances, as well as ontological dependencies and norms of the production and consumption of Web content.

Organizational Semiotics studies the nature, characteristics, function, and effect of information and communication in organizational contexts. An organization is considered a social system in which people behave in an organized manner by conforming to a certain system of norms [2]. Among the methods employed by the OS community is a set of methods known as MEASUR (Methods for Eliciting, Analyzing, and Specifying Users' Requirements) [2, 4]. The SAM is one of the MEASUR methods which focus on the agents and their pattern of behaviors.

In addition to the SAM, the NAM [3] is used to describe the relationships between an intentional use of signs and the resulting behavior of responsible agents in a social context. The behavioral norms express how people behave in regular patterns, e.g., for reading and writing on the Web.

In this study, the above-mentioned methods were adapted to be used in participatory practices with people with hearing loss. The study was performed using the following 4-step method: (1) Individual Interview, (2) Semantic Analysis, (3) Norm Analysis and Problem Synthesis, and (4) Participatory Solutions Proposal. Based on the findings, the article proposes high level design recommendations for enhancing accessibility for people with hearing loss, and discusses research challenges.

This paper is structured as follows: the second section defines key concepts used in this work, and presents the theoretical and methodological foundations of SAM and NAM; the third section presents the study methodology, including its context and subjects; the fourth section presents and discusses the results; and the fifth section concludes the paper.

\section{Concepts and Methodological Foundations}

In this section, we focus on introducing key concepts adopted in the paper, including the deaf literacy problem (subsection 2.1) and the accessibility on the web (subsection 2.2). This section also presents the theoretical and methodological foundations of SAM and NAM (subsection 2.3).

\subsection{Deaf Literacy}

The deafness concept (a degree of Hearing impairment) is associated with the inability to understand speech, even with amplification, i.e., the individual is impaired in processing linguistic information through hearing [5]. Face to face communication usually occurs during spoken language, however deaf people communicate primarily 
using gestures. Written language can be considered a second language for many, as a deaf persons' first language is usually Sign Language [6]. Studies highlight that diagnose and treatment of hearing impairment should be done during early years of child development to stimulate Neuroplasticity ${ }^{1}$. Early contact with sign language and other forms of expressions (e.g., written language) should be stimulated.

In practice, there are many people who are born with hearing impairment and achieve high levels of literacy skills. However, language skills vary from person to person. Furthermore, people (with or without hearing loss) are continually learning and improving their language skills due to new knowledge and experiences. According to [7], in Brazil only 7\% of deaf people know how to read and write in Portuguese. One of the causes of this low literacy rate is the fact that literacy skills are frequently not taught in two languages at the same time.

In Bilingual deaf education, the students learn sign language as their first language, and written/spoken language as their second. In Brazil, Libras was recognized relatively late as a national language; nowadays, the use of Libras in education and government services is mandatory ${ }^{2}$. Nevertheless, according to some studies [e.g., 8], the Portuguese language is mostly an exclusive language for acquisition and knowledge sharing. In [8] the authors emphasize the need to promote the inclusion of the deaf community in the development of educational polices.

\subsection{Hearing Loss and Web Accessibility}

Previous studies (e.g., [1]) highlighted that the written language is a serious barrier for using the Web; for example, in situations where there are long and complex texts. Many deaf users read "word by word" trying to understand the meaning by associating each word with a sign that they already know. Another problem is the existence of many technical and typical Internet terms. The "Internet slang" (or Cyber-slang) is a barrier, because formal grammatical rules that can be learned (memorized) are commonly substituted by phonetic based constructions in the Portuguese language. Furthermore, some $\mathrm{W} 3 \mathrm{C}$ recommendations such as the use of short and simple text are not always possible or easy to be followed by content producers.

There are various Assistive Technologies (AT) for supporting meaningful interactions on the Web. AT solutions for users with hearing loss range from simple caption editors to complex video generators, which translate the written text into sign language videos. These AT solutions are certainly an important mechanism for including people with hearing loss on the Web. However, in addition to AT, there is a need for research to be developed in the field of Web design, which will probably require new AT solutions.

Some studies argue that it necessary to promote the participation of users in the design process to provide properly accessible solutions [9]. One of the most difficult aspects is how to interact with the people that will use the interfaces in a proper way,

\footnotetext{
${ }^{1}$ Capacity of the neural system to reorganize due to learning activities or injuries.

${ }^{2}$ Law 10.436, April 24, 2002.

http: / /www.planalto.gov.br/ccivil_03/Leis/2002/L10436.htm
} 
i.e., promoting the direct participation of all in the design process [10]. The development of appropriate practices and modeling methods for supporting the participatory design of accessible Web content is an open research issue.

As mentioned above, our previous studies [1] highlighted many difficulties for people with loss. The paper presented a study performed in two steps with 21 participants: (1) questionnaire and situation/scenario description, and (2) participatory evaluation of problems and barriers for using the Web. However, the study was limited to a conceptualization of the problem (by using the Semiotic Framework) and the identification of problems, questions, and solutions (by using the Evaluation Framing). This paper goes one step further by systematically studying problems related to normative aspects by using the SAM and NAM as methodological reference.

\subsection{SAM and NAM Concepts}

As part of MEASUR, SAM focuses on the agents and their pattern of behaviors. Some basic concepts of SAM adopted in this work are [2]:

- "Affordance", the concept originally introduced by Gibson [3] to express the behavior of an organism made available by some combined structure of the organism and its environment, was expanded by Stamper [11] to include invariants of the social world. Social affordances arise from the norms we share with people around us. Stamper argues that reality as we know it was not constructed individually; it was created by cultural development over millenniums. For example, a cup is a human artifact. Its use is not only possible because of its physical aspect but also because of its social affordances (children have learned to use it for drinking, instead of throwing it at someone);

- "An agent" is defined as something (e.g., a person, a cultural group or an organization) that has responsible behavior. Agents are affordances that can take responsibility both for their own actions and for the actions of others;

- "Role-name" is the role of the agents according to the affordances for which they are in charge. For example, the "content producer" is a person in charge of the "content";

- "An ontological dependency" is formed when an affordance is possible only if certain other affordances are available. For example, for a person to be able to stumble, he/she must first walk;

- "Determiners" are invariants of quality and quantity that differentiate one instance from another. For example, text size.

The concepts used in Semantic Analysis are represented by means of ontology charts, which have a graphical notation to represent agents (circles), affordances (rectangles), ontological dependencies (lines drawn from left to right), role-names (parentheses), whole-part relations (dot), and determiners (\#).

The NAM focuses on social, cultural, and organizational norms that govern the actions of agents in the business domain. At the social level, norms describe beliefs, expectations, commitments, contract, law, culture, as well as business [2]. 
According to Liu [2] one way to categorize norms is according to how norms "control" human behavior (i.e., tendency of behaving in a certain way). Several norms can be identified in this way, each of which "governs" a certain aspect of human behavior. The behavioural norms, analyzed in this study, represent how people behave in regular patterns. People's behavior is affected by social conventions, law, standard procedures, among other aspects. The following example illustrates a behavioural norm description (using the formalism presented by [2]) in the context of this paper:

Whenever someone is using a wiki

if is writing a post

then content producer

is obliged to

to use the correct verbal tense

This formalism can be used to represent norms for Web content production and consumption in an organizational context; however it is worth mentioning that the behavioral norms are not understood (from the OS perspective) as a guide or handbook; they are linked to actual expected behavior agents in society. Stamper [12] emphasizes that norms can be understood as a "force field" that leads the agents to behave in a certain way; therefore norms are not concrete objects.

\section{$3 \quad$ Methodology}

This section presents the methodology employed in the study reported in this paper. Section 3.1 presents the subject and context where the study was performed. Sections 3.2, 3.3, 3.4 and 3.5 present, respectively, the four steps used in the study: Individual Interview, Semantic Analysis, Norm Analysis and Problem Synthesis, and Participatory Solution Proposal.

\subsection{Subject and Context}

The study presented in this paper was conducted in two institutions: the Deaf Service Center in the city of Macapá in Brazil - CAS (Centro de Atendimento ao Surdo), and the Deaf Mission (in Libras) of the Baptist Church of Macapá.

The study started in CAS with 21 participants, named Group 1 (Table 1). This group includes teachers, the director, and students. All the participants of Group 1 had high levels of hearing loss and were fluent in Libras. Nineteen participants $(90 \%)$ had lip-reading skills; however they had different skill levels in the Portuguese language. Considering their educational levels, 14 participants held university degrees and 7 held high school degrees. Their ages ranged from 14 to 44 years old. All the participants declared that they use the internet frequently (more than once a week); nevertheless most of them also declared that they have serious difficulties using the internet. The participants have higher educational levels than the average Brazilian population. They also have high proficiency in sign language.

The Group 2 (Deaf Mission) was composed by 8 participants, including an interpreter. All the participants of Group 2 (Table 2) were fluent in Libras and had lip-reading skills (except for the interpreter). Six participants had high levels of hearing loss and varying skill levels in the Portuguese language. With respect to their educa- 
tional levels, 3 participants held high school degrees and 4 participants were students. Their ages ranged from 12 to 26 years old. Four participants declared that they do not use the internet frequently (more than once a week). All participants (except for the interpreter) also declared that they have serious difficulties using the internet.

Table 1. Participants of the Study - Group 1

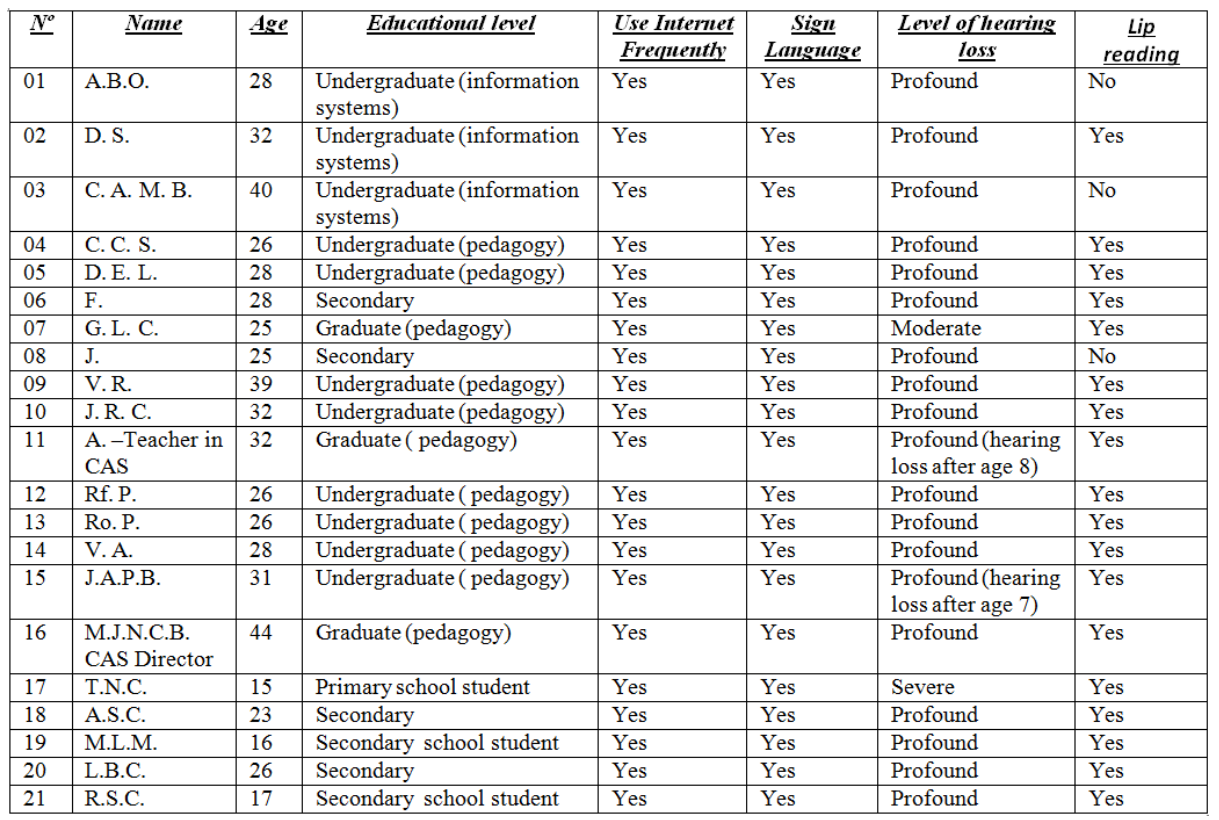

Table 2. Participants of the Study - Group 2

\begin{tabular}{|l|l|c|c|c|c|c|c|}
\hline$\underline{\boldsymbol{N}^{\circ}}$ & $\underline{\text { Name }}$ & $\underline{\text { Age }}$ & $\underline{\text { Educational level }}$ & $\frac{\underline{\text { Use Internet }}}{\underline{\text { Frequently }}}$ & $\begin{array}{c}\underline{\text { Sign }} \\
\text { Language }\end{array}$ & $\underline{\underline{\text { Level of hearing }}}$ & $\begin{array}{c}\text { Lip } \\
\text { reading }\end{array}$ \\
\hline 01 & T.N.C & 15 & Secondary school student & Yes & Yes & Profound & Yes \\
\hline 02 & A.S.C & 23 & Secondary & Yes & Yes & Profound & Yes \\
\hline 03 & A.P & 21 & Secondary & No & Yes & Profound & Yes \\
\hline 04 & J.B & 12 & Secondary school student & Yes & Yes & Profound & Yes \\
\hline 05 & L.B.C & 26 & Adult education primary & No & Yes & Profound & Yes \\
\hline 06 & M.L.M & 16 & Secondary & No & Yes & Profound & Yes \\
\hline 07 & R.S.C & 17 & Adult education secondary & No & Yes & Moderate & Yes \\
\hline 08 & D.- interpret & & & Yes & Yes & No & \\
\hline
\end{tabular}

\subsection{Individual Interview}

The results from the application of the PAM, present in [1], with all participants of Group 1 were used to elaborate the structure and questions of the individual interviews. After the interviews, the groups discussed the issues elicited.

The objective of the individual interviews was to clarify key aspects elicited by the participants. The individual interview was preformed initially with two teacher of CAS (participants 11 and 16 in Table 1). The answers were collected in to steps: they were asked to write their answer on paper and then to discuss with the designers. 
Table 3. Individual Interview Questions

\begin{tabular}{|c|l|}
\hline $\mathbf{N}^{\mathbf{o}}$ & \multicolumn{1}{c|}{ Questions } \\
\hline 1 & What are the computer devices that you have problems using? \\
\hline 2 & Do you use internet search tools? \\
\hline 3 & Do you use social networks? \\
\hline 4 & Can you easily navigate Web pages? What are your difficulties? \\
\hline 5 & $\begin{array}{l}\text { Can you understand the results presented by the search tools? Can you find what you searched } \\
\text { for? }\end{array}$ \\
\hline 6 & Do you enjoy the websites? Do you feel comfortable? \\
\hline 7 & $\begin{array}{l}\text { Do you consider that it is easy to learn how to interact with the websites? Do you easily remember } \\
\text { what you found? }\end{array}$ \\
\hline 8 & Do you frequently need help to interact with the computer? \\
\hline 9 & Describe your experiences using computer systems. \\
\hline 10 & Can you use discussion Forums, where you have to interact simultaneous with other users? \\
\hline 11 & Do you have any additional comment or observation? \\
\hline
\end{tabular}

\subsection{Semantic Analysis}

The semantic analysis began by using problem descriptions synthesized from the answers from individual and group interviews. The affordances were then identified, grouped, and represented in an ontology chart.

The affordances represent the main invariants of behavior necessary to produce and consume Web content. The ontology chart also described the dependencies of each affordance, the main roles, specializations, and part-whole relationships. Each affordance was individually discussed and analyzed in the next step.

\subsection{Norm Analysis and Problem Synthesis}

In addition to the interviews (individual and group), 30 questions regarding grammatical rules and semantic aspects were discussed with the participants. The objective was to identify the most common errors when reading and writing Portuguese texts/posts on the Web. These errors became the basis for modeling a set of behavioral norms for the affordances modeled in the semantic analysis. These norms represent the expected behavior necessary to properly read, write, and interact on the Web.

The norm analysis focused on three types of Web activities: synchronous communication (e.g., Web chat), asynchronous communication (e.g., wiki, blogs and social network posting), and information recovery (using search mechanisms). Each norm was discussed with the participants: they were questioned about the difficulties "to obey/follow" the formal norms. After that, typical writing problems were discussed with the participants (Group 1 and 2) aiming to clarify the reasons behind their mistakes.

\subsection{Participatory Solutions Proposal}

For each norm discussed with the participants, possible high-level design solutions (including the use of AT) were cooperatively developed. The focus was on possible solutions that stimulate learning and the full autonomy of the users. In addition, we conducted a StoryTelling [13] session with Group 1; this participatory practice helped 
us understand the problem and visualize possible solutions. The technique was adapted to facilitate communication, which included the presence of an interpreter to support the conduction of the activities.

A BrainDraw [13] session was then conducted with six participants from Group 1 that declared to have higher skills using the Web. Two participants drew the solutions on paper and four participants used a computer graphics tool. The objective was to produce design alternatives from the users' point of view.

\section{$4 \quad$ Results and Discussion}

Figure 1 presents the ontology chart (simplified) of textual production and consumption. The main agents involved in this task are:

- Society: as the root agents, which means that all the agents and affordances are existentially dependent on that society;

- Person: Person is also a central agent and Hearing is a determiner of a person. The Person agent has two roles:

- Content Producer: The person who produces Web Content: the Designer is a Content Producer;

- Content Consumer: The person who consumes the Web Content;

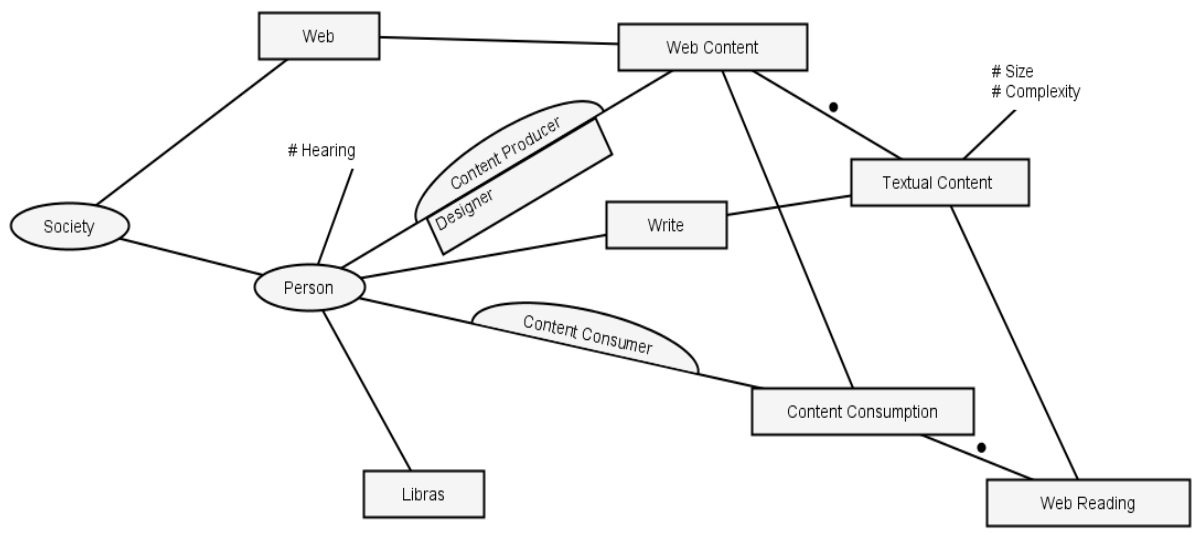

Fig. 1. Ontology Chart of Textual Production and Consumption Overview

Figure 1 also presents the main affordances, ontological dependencies for this task:

- Web: The Web is an affordance of society. The society is in charge of the Web and it is an ontological dependent of the society, i.e., the Web exists while the society exists;

- Write: It is an affordance of a Person;

- Web Content (production): It depends on the existence of the Web and the Content Producer (to produce and maintain it). Textual Content is part of the Web Content and depends on Write. Size and Complexity are examples of determiners of the Textual Content; 


\section{- Content Consumption: It is an affordance of Content Consumer. Web Textual Reading is part of the Content Consumption and depends on Textual Content;}

A total of 121 norms were modeled to formalize the most expressive (according to the users' views) writing and reading rules for the three scenarios (synchronous communication, asynchronous communication, and information recovering). Table 5 illustrates examples of the norms and the respective problems that were identified by the participants as the root cause of norm violations, i.e., the problems represent the users' view of why they violate the norm. Table 5 includes only the norms for reading tasks in synchronous communication tools. Similar tables were constructed for the other scenarios.

Table 4. Norms and primary problems detected on Chart reading

\begin{tabular}{|c|c|c|}
\hline $\mathbf{N}^{\mathbf{0}}$ & Norm & Problem \\
\hline 1 & $\begin{array}{l}\text { Whenever using instant messages tools } \\
\text { if have to read something (in Portuguese) } \\
\text { then "Content Consumer" } \\
\text { is obliged } \\
\text { to understand the general meaning of Portu- } \\
\text { guese sentences }\end{array}$ & $\begin{array}{l}\text { Some users have Libras as their first language, } \\
\text { without the appropriate Portuguese education. }\end{array}$ \\
\hline 2 & $\begin{array}{l}\text { whenever using instant messages tools } \\
\text { if have to read something (in Portuguese) } \\
\text { then Content Consumer" } \\
\text { is obliged } \\
\text { to know the meaning of words (individually) }\end{array}$ & $\begin{array}{l}\text { Deaf people usually know fewer words; frequently in } \\
\text { Brazil they only know basics words. }\end{array}$ \\
\hline 3 & $\begin{array}{l}\text { whenever navigating the Web } \\
\text { if have to read something (in Portuguese) } \\
\text { then "Content Consumer" } \\
\text { is obliged } \\
\text { to know the words' synonym }\end{array}$ & $\begin{array}{l}\text { Frequently this population knows only one meaning } \\
\text { for each word, sometimes it is hard to understand a } \\
\text { synonym, because they usually associate the words } \\
\text { with visual signs }\end{array}$ \\
\hline 4 & $\begin{array}{l}\text { whenever using instant messages tools } \\
\text { if have to read something (in Portuguese) } \\
\text { then "Content Consumer" } \\
\text { is obliged } \\
\text { to know the words figuratively }\end{array}$ & $\begin{array}{l}\text { Commonly users associated the words with the con- } \\
\text { crete meaning of the words }\end{array}$ \\
\hline 5 & $\begin{array}{l}\text { whenever using instant messages tools } \\
\text { if have to read something (in Portuguese) } \\
\text { then "Content Consumer" } \\
\text { is obliged } \\
\text { to know the verbal tense }\end{array}$ & $\begin{array}{l}\text { Usually the verbal tense is not stressed in the Portu- } \\
\text { guese alphabetization for deaf people. It is not easy to } \\
\text { associate the verbal forms to visual elements. }\end{array}$ \\
\hline 6 & $\begin{array}{l}\text { whenever using instant messages tools } \\
\text { if have to read something (in Portuguese) } \\
\text { then "Content Consumer" } \\
\text { is obliged } \\
\text { to know the word from technology }\end{array}$ & $\begin{array}{l}\text { Some words introduced in the Portuguese language } \\
\text { (from technology) have no standard signs in Libras. } \\
\text { Frequently users employ English words during Web } \\
\text { communication. }\end{array}$ \\
\hline 7 & $\begin{array}{l}\text { whenever using instant messages tools } \\
\text { if have to read something (in Portuguese) } \\
\text { then "Content Consumer" } \\
\text { is obliged } \\
\text { to read quickly }\end{array}$ & $\begin{array}{l}\text { Deaf people read each word in isolation making it, } \\
\text { difficult to understand the (complex) text quickly. }\end{array}$ \\
\hline 8 & $\begin{array}{l}\text { whenever using instant messages tools } \\
\text { if have to read something (in Portuguese) } \\
\text { then "Content Consumer" } \\
\text { is obliged } \\
\text { to interpret the language based on phonemes }\end{array}$ & $\begin{array}{l}\text { Phoneme based words are hard to understand. Many } \\
\text { words in internet slang are based on phonemes and } \\
\text { there is no standard translation to Libras. Sometimes } \\
\text { the formal grammatical rules are not obeyed to form } \\
\text { phoneme-based sentences. }\end{array}$ \\
\hline
\end{tabular}


A total of 121 high level design recommendations were produced with the users. These are design solutions that must be implemented by the developers of detailed design solutions, for each specific situation or tool. Table 6 presents the design recommendations for the chat reading problems, i.e., for each norm and problem presented in Table 5 there are respective recommendations in Table 6.

Table 5. Chat design recomendations

\begin{tabular}{|c|c|c|}
\hline $\mathbf{N}^{\mathbf{0}}$ & Elicited Alternatives & Elicited Recommendations \\
\hline 1 & $\begin{array}{l}\text { Minimize the problem with exam- } \\
\text { ples of how to interpret the text. }\end{array}$ & $\begin{array}{l}\text { Include options to explain the meaning of each term and con- } \\
\text { struction of the sentence }\end{array}$ \\
\hline 2 & $\begin{array}{l}\text { Teach by showing the meaning of } \\
\text { the words the suer does not know. }\end{array}$ & $\begin{array}{l}\text { Include options that explain the meaning of the words, exempli- } \\
\text { fying them with contextualized scenarios; those scenarios can be } \\
\text { complemented with visual elements, e.g., using either Libras or } \\
\text { images/videos. }\end{array}$ \\
\hline 3 & $\begin{array}{l}\text { Teach by showing the meaning of } \\
\text { the synonym the user does not } \\
\text { know. }\end{array}$ & $\begin{array}{l}\text { Include options that explain the various meanings of a word, } \\
\text { exemplifying them with contextualized scenarios where it could } \\
\text { be used; those scenarios can be complemented with visual } \\
\text { elements, e.g., using either Libras or images/videos. }\end{array}$ \\
\hline 4 & $\begin{array}{l}\text { Teach by showing the figurative } \\
\text { meaning of the words. }\end{array}$ & $\begin{array}{l}\text { Include options that explain the figurative meaning of a word, } \\
\text { exemplifying them with contextualized scenarios where it could } \\
\text { be used; those scenarios can be complemented by visual ele- } \\
\text { ments, e.g., using either Libras or images/videos. }\end{array}$ \\
\hline 5 & $\begin{array}{l}\text { Minimize the problem with exam- } \\
\text { ples of the verbal tense. }\end{array}$ & $\begin{array}{l}\text { Include options that explain the meaning of each verbal con- } \\
\text { struction for a selected verb, exemplifying them by contextua- } \\
\text { lized scenarios where it could be used; those scenarios can be } \\
\text { complemented by visual elements, e.g., using either Libras or } \\
\text { images/videos. }\end{array}$ \\
\hline 6 & $\begin{array}{l}\text { Teach by showing the meaning of } \\
\text { the words introduced by the tech- } \\
\text { nology. }\end{array}$ & $\begin{array}{l}\text { Include options that explain the meaning of each word intro- } \\
\text { duced by the technology in a sentence, exemplifying them by } \\
\text { contextualized scenarios where it could be used; those scenarios } \\
\text { can be complemented by visual elements, e.g., using either } \\
\text { Libras or images/videos. }\end{array}$ \\
\hline 7 & $\begin{array}{l}\text { Include reading assistance and } \\
\text { automatic translations to help with } \\
\text { quick reading }\end{array}$ & $\begin{array}{l}\text { Include options that help users utilize assistances (e.g., with } \\
\text { hints), text simplifiers and/or Libras translators. }\end{array}$ \\
\hline 8 & $\begin{array}{l}\text { Teach by showing the meaning of } \\
\text { the sentences based on phonemes }\end{array}$ & $\begin{array}{l}\text { Include options that explain the meaning of the sentences based } \\
\text { on phonemes, exemplifying them by contextualized scenarios } \\
\text { where it could be used; those scenarios can be complemented by } \\
\text { visual elements, e.g., using either Libras or images/videos. }\end{array}$ \\
\hline
\end{tabular}

Figure 2 presents an example of the design solution proposed by the users after StoryTelling and Braindraw practices. Designers modeled the solutions based on the design alternatives produced with the participants during the Braindraw sessions. The design solutions illustrate the proposed recommendations. Therefore, the objective was not to develop detailed solutions to be followed, but provide examples to illustrate the recommendations. 


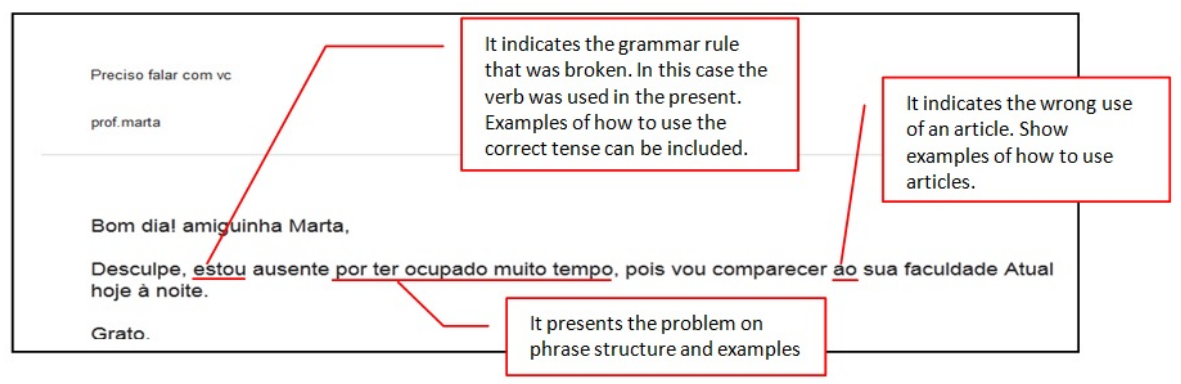

Fig. 2. Example of design solution proposed with the users

We produced a total of 46 interface prototypes with the objective of illustrating the recommendations. Some prototypes grouped the recommendations in a single interface. Considering the three scenarios, the results show that one problem can potentially be repeated in many situations and tools; simultaneously, some solutions may minimize barriers for various different problems. Some recommendations are quite simple and easily developed using existing AT, while others are complex or depend on additional research on new assistive tools.

In general, the results show the potential (as initial experiments) of using the Web to stimulate learning of the written language. These results contradict the idea of creating a separated web or even a translated Web for deaf people. In our view, the role of AT on the Web (e.g., Libras translators, text simplifiers, and dedicated devices) goes beyond providing means to expand perceptual aspects. Its role is also (in a properly design solution) to promote learning and user independency in long term.

However, this work does not present conclusive design solutions. Although some solutions were proposed by the users, more studies should be conducted with the objective of producing complete and standard design recommendations. In particular, there is a need for empirical data about the impacts of using the proposed recommendations on the Web. The effects on learning and users' autonomy can only be precisely analyzed after an extensive period of use by several users.

\section{Conclusion}

Written language is still the predominant means of communication on the Web. Many people with hearing loss have difficulties understanding and producing text-based content. On the Web these difficulties are exacerbated due to the use of technical terms, internet slang, and the demand for reading and writing quickly (especially on synchronous communication tools). In this paper, we have analyzed the barriers for users with hearing loss while using the Web. A study, using SAM and NAM as the methodological reference, was performed with 29 users and focused on the elicitation of barriers when producing and consuming Web content. A total of 129 norms were developed by the users. These norms represent commonly expected behaviors that are not followed due to problems users have during synchronous communication, asynchronous communication, and information recovering tasks. Participatory practices 
were conducted for the elicitation of alternatives, and for the high level design of recommendations according to the users' point of view. The proposed recommendations can be seen as a set of design issues to be deeply explored in the future.

As a next step, we propose the implementation of prototypes with the elicited recommendations, followed by empirical studies with the users. The results from the empirical studies can be used in an interactive process to improve the recommendations.

\section{References}

1. Ferreira, M.A.M., Bonacin, R.: Analyzing Barriers for People with Hearing Loss on the Web: A Semiotic Study. In: Stephanidis, C., Antona, M. (eds.) UAHCI/HCII 2013, Part II. LNCS, vol. 8010, pp. 694-703. Springer, Heidelberg (2013)

2. Liu, K.: Semiotics in information systems engineering. Cambridge University Press (2000)

3. Gibson, J.J.: The Theory of Affordances. In: Shaw, R., Bransford, J. (eds.) Perceiving, Acting, and Knowing (1977)

4. Stamper, R.: Social Norms in Requirements Analysis - an outline of MEASUR. In: Jirotka, M., Goguen, J., Bickerton, M. (eds.) Requirements Engineering, Technical and Social Aspects. Academic Press, New York (1993)

5. Elzouki, A.Y., Harfi, H.A., Nazer, H., Oh, W., Stapleton, F.B., Whitley, R.J.: Textbook of Clinical Pediatrics, vol. 1. Springer (2011)

6. Power, D., Leigh, G.R.: Principles and practices of literacy development for deaf learners: A historical overview. Journal of Deaf Studies and Deaf Education 5, 3-8 (2000)

7. Moura, G., Vasconcelos, L.A., Cavalcanti, A., Breyer, F., da Silva, D., Teixeira, J.M., Leão, C., Kelner, J.: Luz, Câmera, Libras!: How a Mobile Game Can Improve the Learning of Sign Languages. In: Marcus, A. (ed.) DUXU/HCII 2013. LNCS, vol. 8013, pp. 266-275. Springer, Heidelberg (2013)

8. Fernandes, E.: Surdez e Bilinguismo, 4th edn., Editora Mediação. Porto Alegre (2011)

9. Keates, S., Looms, P.O.: User -Centered design and accessibility in real-world contexts. HCI Tutorial. Springer, Heidelberg (2013)

10. Fuglerud, K.S., Sloan, D.: The Link between Inclusive Design and Innovation: Some Key Elements. In: Kurosu, M. (ed.) HCII/HCI 2013, Part I. LNCS, vol. 8004, pp. 41-50. Springer, Heidelberg (2013)

11. Stamper, R.: Signs, Information and Systems. In: Holmqnist, B., et al. (eds.) Signs of Work Semiotics Information Processing in Organisations. Walter de Gruyter, N. Y (1996)

12. Stamper, R.K.: Information Systems as a Social Science: An Alternative to the FRISCO Formalism. In: Falkenberg, E.D., Lyytien, K., Verrijn-Stuart, A.A. (eds.) Information System Concepts: an Integrated Discipline Emerging, pp. 1-51. Kluwer Academic Publishers, USA (2000)

13. Müller, M.J., Haslwanter, J.H., Dayton, T.: Participatory Pratices in the Software Lifecycle. In: Helander, M., Landauer, T.K., Prabhu, P. (eds.) Handbook of HumanComputer Interaction, 2nd edn., pp. 255-297. Elsevier Science (1997) 